KLEIST-JAHRBUCH 1999 


\title{
KLEIST-JAHRBUCH 1999
}

\author{
Im Auftrag des Vorstandes \\ der Heinrich-von-Kleist-Gesellschaft \\ herausgegeben von \\ Günter Blamberger \\ (verantwortlich für \\ Abhandlungen, Beiträge \\ der Jahrestagung 1998, Miszellen) \\ sowie \\ Sabine Doering und Klaus Müller-Salget \\ (verantwortlich für Rezensionen)
}

VERLAG J. B. METZLER

STUTTGART · WEIMAR 
Anschrift der Redaktion:

Ingo Breuer, Bernhard Dotzler, Regina Jorde

Universität zu Köln, Institut für deutsche Sprache und Literatur,

Albertus-Magnus-Platz, D-50923 Köln

Die Deutsche Bibliothek - CIP-Einheitsaufnabme

Kleist-Jahrbuch ... / - Stuttgart: Metzler.

Erscheint jährlich. - Früher im Verl. E. Schmidt, Berlin. -

Aufnahme nach 1990 (1991)

ISSN 0722-8899

1990 (1991) -

Verl.-Wechsel

ISBN 978-3-476-01709-3

ISBN 978-3-476-03787-9 (eBook)

DOI 10.1007/978-3-476-03787-9

Dieses Werk einschließlich aller seiner Teile ist urheberrechtlich geschützt.

Jede Verwertung außerhalb der engen Grenzen des Urheberrechtsgesetzes ist ohne Zustimmung des Verlages unzulässig und strafbar. Das gilt insbesondere für Vervielfältigungen, Übersetzungen, Mikroverfilmungen und die Einspeicherung und Verarbeitung in elektronischen Systemen.

(C) 2000 Springer-Verlag GmbH Deutschland

Ursprünglich erschienen bei J.B.Metzlersche Verlagsbuchhandlung und Carl Ernst Poeschel Verlag GmbH in Stuttgart 2000 


\section{INHALT}

\section{Verleibung des Kleist-Preises 1998}

Günter Blamberger: Rede zur Verleihung des Kleist-Preises an Dirk von Petersdorff im Deutschen Schauspielhaus in Hamburg am 13. Juni 1998

Lars Gustafsson: Laudatio auf Dirk von Petersdorff. Anläßlich der Verleihung des Kleist-Preises am 13. Juni $1998 \ldots \ldots \ldots \ldots \ldots \ldots \ldots \ldots$

Dirk von Petersdorff: Rede zur Verleihung des Kleist-Preises $\ldots . \ldots \ldots \ldots \quad 14$

\section{Internationale Jabrestagung in Hamburg 1998: 'Kleists Dueller (Folge 2)}

Günter Blamberger: Agonalität und Theatralität. Kleists Gedankenfigur des Duells im Kontext der europäischen Moralistik

Gesa von Essen: Römer und Germanen im Spiel der Masken. Heinrich von

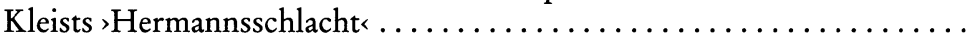

Martin Dönike: »... durch List und den ganzen Inbegriff jener Künste, die die Notwehr dem Schwachen in die Hände gibt«. Zur Gedankenfigur der Notwehr bei Kleist . ...........................

Sibylle Peters: Wie Geschichte geschehen lassen? Theatralität und Anekdotizität in den $>$ Berliner Abendblättern $\ldots \ldots \ldots \ldots \ldots \ldots \ldots \ldots$

Bianca Theisen: Der Bewunderer des Shakespeare. Kleists Skeptizismus ....

Gabriele Brandstetter: Duell im Spiegel. Zum Rahmenspiel in Kleists

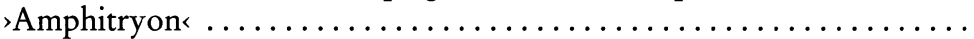

Claudia Benthien: Gesichtsverlust und Gewaltsamkeit. Zur Psychodynamik von Scham und Schuld in Kleists >Familie Schroffenstein ‘ . . . . . . 128

Michael Ott: »... ich will keine andre Ehre mehr, als deine Schande ...«. Zu Ehre, Duell und Geschlechterdifferenz in Kleists Erzählungen ..... 
Elisabeth Bronfen: Liebeszerstückelung: >Penthesilear mit Shakespeare

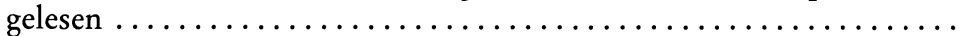

Marianne Schuller: Pfeil und Asche. Zu Kleists Erzählung `Der Zweikampf`

Wolfgang Struck: Schwarz - Weiß - Rot, oder: »Lernt des Verräthers Mitleid in Domingo «. >Die Verlobung in St. Domingo zwischen Befreiungskrieg und Kolonialismus ...............................

Ute Frevert: Die Sprache der Ehre. Heinrich von Kleist und die Duellpraxis seiner Zeit

\section{Abbandlung}

Ulrich Fülleborn: Die Geburt der Tragödie aus dem Scheitern aller Berechnungen. Die frühen Briefe Heinrichs von Kleist und >Die Familie

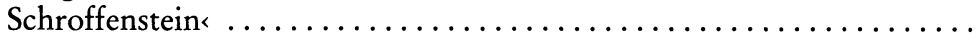

\section{Realien}

Hermann F. Weiss: Eine neuentdeckte Fassung von Heinrich von Kleists >Das letzte Lied.

\section{Rezensionen}

Peter Philipp Riedl: Die Geburt der Poesie aus dem Geist der Landschaftsbetrachtung (über: Hilda Meldrum Brown, Heinrich von Kleist: The Ambiguity of Art and the Necessity of Form)

Joachim Rückert: Kohlhase statt Kohlhaas (über: Christoph Müller-Tragin, Die Fehde des Hans Kohlhase. Fehderecht und Fehdepraxis zu Beginn der frühen Neuzeit in den Kurfürstentümern Sachsen und Brandenburg)

Fritz Hackert: Die unendliche Dreiecksgeschichte (über: Justus Fetscher, Verzeichnungen. Kleists >Amphitryon 〈 und seine Umschrift bei Goethe und Hofmannsthal)

Peter Horn: Bilder des Fremden (über: Gesa von Essen, Hermannsschlachten. Germanen- und Römerbilder in der Literatur des 18. und 19. Jahr-

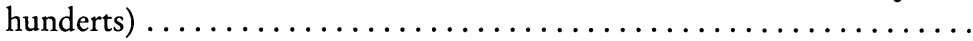


Eike Behrendt: Romantische Jugend? (über: Jugend. Ein romantisches Konzept? Hg. von Günter Oesterle) . . . . . . . . . . . . . . . . . . 293

Siglenverzeichnis ...................................... 299

Anschriften der Mitarbeiterinnen und Mitarbeiter ................. 300

Informationen zur Heinrich-von-Kleist-Gesellschaft . . . . . . . . . . . 302 